\title{
Relationships among Body Mass Index, Activities of Daily Living and Zinc Nutritional Status in Disabled Elderly Patients in Nursing Facilities
}

\author{
Kazue KosAKA ${ }^{1,2}$, Sachiko YAMASHITA ${ }^{3}$, Chinatsu ANDO ${ }^{3}$, Yoriaki ENDO ${ }^{4}$, \\ Keiko TANIGUCHI ${ }^{4}$ and Shigeshi KIKUNAGA ${ }^{2,5}$ \\ ${ }^{1}$ Mimasaka University, 50, Kitazono-cho, Thuyama, Okayama 708-8511, Japan \\ ${ }^{2}$ Notre Dame Seishin University, Graduate School, 2-16-9, Ifuku-cho, Kita-ku, \\ Okayama 700-8516, Japan \\ ${ }^{3}$ Health Facility, Shououen, 242-1, Taira, Shoo-cho, Katsuta-gun, Okayama 709-4344, Japan \\ ${ }^{4}$ Health Facility, Sakuto, 280, Emi, Mimasaka, Okayama 709-4234, Japan \\ ${ }^{5}$ Notre Dame Seishin University, 2-16-9, Ifuku-cho, Kita-ku, Okayama 700-8516, Japan
}

(Received March 14, 2013)

\begin{abstract}
Summary The purpose of this study was to examine the relationship between the zinc nutritional status and the factors associated with serum zinc concentration in the elderly patients in two nursing facilities: body mass index (BMI), the level of care, the grade of bedriddenness, and the grade of cognitive function. The estimations of the hematological constituents, physical index, and dietary survey were made based on the examination carried out of the 26 disabled elderly patients (male 6 , female 20, mean age $90 \pm 6$ y). The results obtained from this study can be summarized as follows: 1) The low activities of daily living (ADL) group showed a low level of serum zinc concentration, although the uptake rate of zinc by subjects was shown to be high when compared to the Dietary Reference Intakes 2010. 2) The high ADL group showed a high level of serum zinc concentration. 3) The results of multiple regression analysis among the serum zinc concentration, the determined serum ingredients, and the physical characteristics showed the significant correlation of serum zinc concentration against the BMI, the level of care, height, Alb and iron values. 4) The BMI, the level of care, the grade of bedriddenness, and the grade of cognitive function of the subjects changed according to the zinc nutritional status. These results suggested that the actual requirements of zinc of the subjects were different according to the BMI, the level of care, the grade of bedriddenness, and the grade of cognitive function.
\end{abstract}

Key Words serum zinc concentration, BMI, level of care, grade of bedriddenness, grade of cognitive function

Protein-energy malnutrition (PEM) is an important factor in regard to the nutritional management of disabled elderly patients. According to the four studies conducted on the effects of PEM on the physical status of disabled elderly patients, it has been indicated that elderly persons with malnutrition having a serum albumin level of less than $3.5 \mathrm{~g} / \mathrm{dL}$ have a higher mortality rate than elderly persons with proper nutrition (1), have a lower index of activities of daily living (ADL) (2), and have longer hospitalization times (3). PEM patients in their seventies have also been observed to demonstrate remarkably lower immunity in comparison with healthy persons of the same age (4). In addition, according to another study on the correlation between PEM risk and level of care targeted at elderly persons age 65 and over hospitalized or residing at a combined type care facility for the elderly (5), the proportion of subjects at risk for PEM having a serum albumin level of $3.5 \mathrm{~g} / \mathrm{dL}$ or less is remarkably larger with subjects having a level of care of 4 or 5 than with those having a level of care of 1,2 or 3 .

E-mail: kosaka@mimasaka.ac.jp
On the other hand, the presence of zinc deficiency has been indicated to be a symptom of PEM among the elderly (6). Zinc is known to play an important role in DNA and protein synthesis as well as in the immune system (7). In addition, it has been reported that serum zinc levels decrease with age $(8)$ and that they are low in hospitalized patients and debilitated elderly persons in particular (9-12). According to the studies conducted on the effects of serum zinc levels on the physical status of the elderly, 1) their survival rate decreases significantly (13), 2) ADL indices also decrease (13), 3) infections occur when they are in long-term hospitalization (11) and 4) immunity also decreases (14) in response to low serum zinc levels. As has been described above, similar symptoms have been reported among the elderly with PEM and low serum zinc levels. To depress the rate of mortality and to increase the ADL index and immunity for elderly patients, it is therefore necessary to improve PEM and maintain a favorable zinc nutritional status.

Based on these findings of the reports, Kosaka et al. conducted a study focusing on the correlation between zinc nutritional status and physical status affecting 
Table 1. Characteristics of the subjects.

\begin{tabular}{|c|c|c|c|c|c|c|c|c|c|c|c|}
\hline $\begin{array}{l}\text { Subject } \\
\text { number }\end{array}$ & Age & Sex & $\begin{array}{c}\text { Body } \\
\text { weight } \\
\text { (kg) }\end{array}$ & $\begin{array}{l}\text { Height } \\
(\mathrm{cm})\end{array}$ & $\begin{array}{l}\text { Body mass } \\
\text { index }\end{array}$ & $\begin{array}{c}\text { Basal metabolic } \\
\text { rate } \\
(\mathrm{kcal} / \mathrm{d})\end{array}$ & $\begin{array}{l}\text { Level of } \\
\text { care }\end{array}$ & $\begin{array}{c}\text { Grade of } \\
\text { bedriddenness }\end{array}$ & $\begin{array}{l}\text { Grade of } \\
\text { cognitive } \\
\text { function }\end{array}$ & $\begin{array}{l}\text { Type of } \\
\text { feeding }\end{array}$ & $\begin{array}{c}\text { Type of } \\
\text { diet }\end{array}$ \\
\hline 1 & 73 & M & 60.7 & 165.0 & 22.3 & 1,305 & 2 & B1 & IIa & Orally & Regular \\
\hline 2 & 92 & M & 49.2 & 153.0 & 21.0 & 1,058 & 2 & B1 & IIIb & Orally & Regular \\
\hline 3 & 93 & M & 59.3 & 155.0 & 24.7 & 1,275 & 2 & B1 & I & Orally & Regular \\
\hline 4 & 81 & $\mathrm{~F}$ & 40.4 & 145.0 & 19.2 & 836 & 2 & A1 & $\mathrm{IIb}$ & Orally & Regular \\
\hline 5 & 90 & $\mathrm{~F}$ & 42.5 & 143.0 & 20.8 & 880 & 2 & $\mathrm{~A} 2$ & $\mathrm{IIb}$ & Orally & Regular \\
\hline 6 & 95 & F & 46.3 & 149.0 & 20.9 & 958 & 2 & $\mathrm{~A} 2$ & IIIa & Orally & Rice gruel \\
\hline 7 & 82 & M & 53.0 & 163.0 & 19.9 & 1,140 & 3 & B2 & $\mathrm{IIb}$ & Orally & Rice gruel \\
\hline 8 & 92 & M & 46.2 & 163.0 & 17.4 & 993 & 3 & $\mathrm{~B} 2$ & IIa & Orally & Rice gruel \\
\hline 9 & 83 & $\mathrm{~F}$ & 51.9 & 140.0 & 26.5 & 1,074 & 3 & B1 & I & Orally & Regular \\
\hline 10 & 87 & $\mathrm{~F}$ & 37.2 & 142.0 & 18.4 & 770 & 3 & B1 & $\mathrm{IIb}$ & Orally & Regular \\
\hline 11 & 91 & F & 45.1 & 132.4 & 25.9 & 934 & 3 & B2 & IIa & Orally & Rice gruel \\
\hline 12 & 91 & F & 44.4 & 142.0 & 22.0 & 919 & 3 & B1 & IIa & Orally & Regular \\
\hline 13 & 83 & M & 38.0 & 156.0 & 15.6 & 817 & 4 & $\mathrm{C} 1$ & IIIa & Enterally & \\
\hline 14 & 84 & $\mathrm{~F}$ & 32.9 & 149.0 & 14.8 & 681 & 4 & $\mathrm{C} 2$ & IIIb & Enterally & \\
\hline 15 & 89 & F & 29.4 & 142.0 & 14.6 & 609 & 4 & $\mathrm{C} 2$ & IV & Enterally & \\
\hline 16 & 91 & $\mathrm{~F}$ & 35.8 & 130.0 & 21.2 & 741 & 4 & B1 & $\mathrm{IIb}$ & Orally & Rice gruel \\
\hline 17 & 93 & F & 35.8 & 142.0 & 17.8 & 741 & 4 & $\mathrm{~B} 2$ & $\mathrm{IIb}$ & Orally & Rice gruel \\
\hline 18 & 94 & F & 37.2 & 150.0 & 16.5 & 770 & 4 & B2 & IIIb & Orally & Regular \\
\hline 19 & 95 & $\mathrm{~F}$ & 36.1 & 145.0 & 17.2 & 747 & 4 & $\mathrm{C} 1$ & IIIa & Orally & Rice gruel \\
\hline 20 & 81 & F & 39.0 & 140.0 & 19.9 & 807 & 5 & $\mathrm{C} 2$ & IV & Orally & Rice gruel \\
\hline 21 & 90 & F & 30.7 & 138.0 & 16.2 & 635 & 5 & $\mathrm{C} 2$ & IIIb & Enterally & \\
\hline 22 & 91 & $\mathrm{~F}$ & 39.5 & 150.0 & 17.6 & 818 & 5 & $\mathrm{C} 2$ & IIIb & Enterally & \\
\hline 23 & 93 & $\mathrm{~F}$ & 40.6 & 145.0 & 19.3 & 840 & 5 & $\mathrm{C} 2$ & IIIb & Enterally & \\
\hline 24 & 94 & $\mathrm{~F}$ & 35.7 & 133.0 & 20.3 & 739 & 5 & B2 & IIIb & Orally & Regular \\
\hline 25 & 99 & $\mathrm{~F}$ & 36.3 & 139.0 & 18.8 & 751 & 5 & $\mathrm{C} 2$ & IV & Enterally & \\
\hline 26 & 100 & F & 30.9 & 140.0 & 15.7 & 640 & 5 & $\mathrm{C} 2$ & IIIa & Enterally & \\
\hline Mean & 90 & & 41.3 & 145.8 & 19.4 & 865 & 4 & & & & \\
\hline $\mathrm{SD}$ & 6 & & 8.3 & 9.2 & 3.2 & 185 & 1 & & & & \\
\hline
\end{tabular}

$\mathrm{M}$ means male and $\mathrm{F}$ means female.

quality of life (QOL) in disabled elderly patients in nursing facilities. First, a study was conducted on the correlation among zinc intake, serum zinc levels, and blood component levels related to serum zinc levels (15). As a result, it was found that the level of zinc intake was approximately the recommended dietary allowance level in the Dietary Reference Intakes for Japanese, 2010 (to be referred to as the Dietary Reference Intakes) (16) and the value recommended indicated in the National Health and Nutrition Survey, 2004 (17). But it was also found that the serum zinc levels of a high proportion of subjects undergoing oral feeding and enteral feeding were equal to or lower than the reference values. In addition, in a low serum zinc level group, blood component levels consisting of erythrocyte (RBC), hemoglobin (Hb), hematocrit $(\mathrm{Ht})$, total protein (TP) and albumin (Alb) levels did not reach the values reported in the National Health and Nutrition Survey (17).

Next, another study was conducted on the correlation among zinc nutritional status, the level of care, and physical status (18). As a result, although zinc intake approximated the recommended dietary allowance level indicated in the Dietary Reference Intakes (16), serum zinc levels tended to be low both in a group with body mass index (BMI) under 18.5 and in a group receiv- ing a heavy level of care. Based on the findings of these studies, it was suggested that the protein and iron nutritional status and also ADL of disabled elderly patients in nursing facilities were intimately related to zinc nutritional status.

Therefore, another more detailed investigation was conducted in different nursing facilities from the preliminary study (18). The purpose of this investigation was to examine the relationships among the zinc nutritional status, the level of care, the physical status, and the mental status. The physical status means the grade of bedriddenness and the mental status means the grade of cognitive function. It was examined as to the manner in which serum zinc level, which is used as an indicator of zinc nutritional status, changes according to the four factors BMI, level of care, and the grades of physical status and mental status.

\section{SUBJECTS AND METHODS}

Study subjects and study period. The subjects of this study consisted of 26 disabled elderly patients residing at two nursing facilities (including 6 males and 20 females, average age: $90 \pm 6 \mathrm{y}$ ). The subjects of the study were provided with an explanation of the study, after which informed consent to participate in the study 
was obtained in writing either from the subject or family member (but only from a family member in cases in which it was difficult to ascertain the intentions of the subject). The contents of the informed consent form indicated the purpose and significance of the study, a description of the contents of the study and methods used, advantages and disadvantages resulting from participation in the study, that the subjects were able to withdraw from the study at any time in accordance with their wishes even if the study was still in progress, and that they would not incur any expenses for participating in the study. In addition, the subjects were also provided with an explanation that personal information would be managed with the strictest confidentiality, that their personal information would be discarded following statistical processing, and that data obtained from statistical processing would be used in presentations. The attributes of the subjects are shown by gender in Table 1. Furthermore, the body weights of the subjects (as measured using a wheel chair scale), height (as measured with the five point method (19) using a measuring tape), level of care, grade of independent living for the elderly and disabled (to be referred to as the grade of bedriddenness), and the grade of independent living for the cognitively functioning elderly (to be referred to as the grade of cognitive function) were confirmed from the subjects' medical records. Furthermore, the level of care was determined by the committee for certification of need of the nursing insurance system in Japan (20). In addition, the grade of bedriddenness was determined according to the criteria for evaluating the grade of independence in activities of daily living (21), the grade of cognitive function was determined according to the criteria for evaluating cognitive function (21).

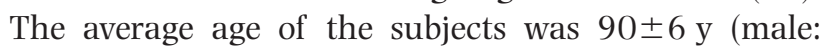
$86 \mathrm{y}$, female: $91 \mathrm{y}$ ), and their average physique at the start of the survey consisted of an average body weight of $41.3 \pm 8.3 \mathrm{~kg}$ (male: $51.1 \mathrm{~kg}$, female: $38.4 \mathrm{~kg}$ ), average height of $145.8 \pm 9.2 \mathrm{~cm}$ (male: $159.2 \mathrm{~cm}$, female: $141.8 \mathrm{~cm}$ ), and average BMI of 19.4 3.2 (male: 20.2, female: 19.2). Basic metabolic rates were calculated by multiplying subject body weight by basic metabolic rate standard values according to gender and age. The average value of the basic metabolic rates of the subjects was $865 \pm 185 \mathrm{kcal} / \mathrm{d}$ (male: $1,098 \mathrm{kcal} / \mathrm{d}$, female: $795 \mathrm{kcal} / \mathrm{d}$ ). The average value of level of care was $4 \pm 1$ (male: 3, female: 4 ). With respect to the grade of bedriddenness, 3 females were of rank A, 13 subjects were of rank $\mathrm{B}$ ( 5 males and 8 females), and 10 subjects were of rank $\mathrm{C}$ ( 1 male and 9 females). With respect to the grade of cognitive function, 2 subjects were of rank I (1 male and 1 female), 10 subjects were of rank II ( 3 males and 7 females), 11 subjects were of rank III ( 2 males and 9 females), and 3 females were of rank IV. With respect to the feeding methods used among the subjects, 18 subjects were fed orally ( 5 males and 13 females), and 8 subjects were fed enterally ( 1 male and 7 females). In addition, with respect to diet types, 10 subjects were given a regular diet ( 3 males and 7 females), while 8 subjects were given rice gruel diet ( 2 males and 6 females).
Nutrient preparations used for enteral feeding consisted of MA-R2.0 (Clinico Co., Ltd.) (22) and Sanet SA (Sanwa Kagaku Kenkyusho Co., Ltd.) (22).

This study was conducted with the approval of the research ethics committee of Mimasaka University (approval date: September 26, 2011). This study was conducted based on ethical guidelines relating to clinical research (Ministry of Health, Labour and Welfare, revised on July 31,2008 ) in the spirit of the Declaration of Helsinki. Furthermore, the study period was a period of 1 mo from November 14, 2011 to December 13, 2011.

Dietary survey and blood tests. Nutrient intake levels for the 1-mo study period were calculated from intake levels for breakfast, lunch and dinner found both in the meal menu charts and the subjects' medical records. The calculated 1-mo nutrient intake levels were then converted to levels per day. The Fifth Revised and Enlarged 2005 Standard Excel Eiyokun software program (Kenpakusha Co., Ltd.) was used to calculate nutrient intake levels. Furthermore, the nutrient levels contained in regular diets were determined on the basis of the Dietary Reference Intakes (23). The menus and enteral feeding administration plans used at the facilities where the study was conducted were prepared based on level I physical activity for an age group of $70 \mathrm{y}$ or older as defined in the Dietary Reference Intakes (16). The menus were the same for the regular diet and rice gruel diet of the oral feeding group. However, the weight of the rice used in the rice gruel diet was lower in order to make calorie intake lower than that of the regular diet. In addition, the dosages of nutrient preparations used in the enteral feeding group were adjusted in correspondence to the activity level of each subject. Thus, protein, zinc and other nutrient dosages differed according to the activity level of each subject.

Therefore, the nutrient intake levels of the subjects were indicated as a percentage of the Daily Reference Intakes (16) together with the nutrition evaluations ordinarily used at elderly health care facilities.

Blood tests consisted of measurement of zinc, leukocytes (WBC), RBC, Hb, Ht, TP, Alb, A/G ratio, iron and copper concentrations were performed once during the study period. Blood samples are preferably collected while subjects are fasting early in the morning. However, it was difficult for the participating facilities to collect blood specimens from a large number of subjects all at once while they were fasting early in the morning. Therefore, in consideration of diurnal variations in serum zinc levels (24), blood samples were collected from 14:00 to 15:00. The collection site was either the cubital vein or superficial vein in the back of the hand or back of the foot. Furthermore, measurement of blood component levels was commissioned to an analysis center (Okayama Medical Laboratory). Serum zinc levels were measured by atomic absorption spectrometry.

Statistical processing. Nutrient intake levels were indicated as a percentage of the recommended dietary allowance, adequate intake or tentative dietary goal of the Dietary Reference Intakes (16). All results obtained 
o

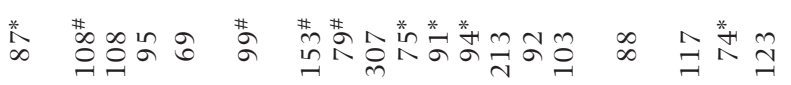
6 (1)

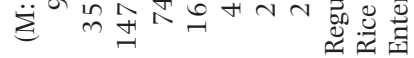

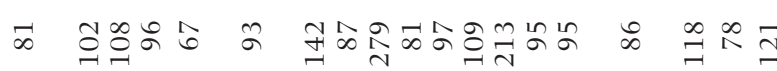
¿ म म

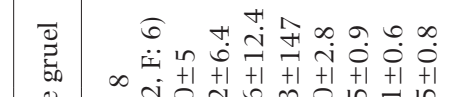

$\ddot{\Sigma}^{\circ}$ भi

in in

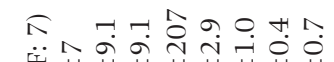

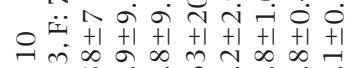

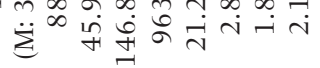

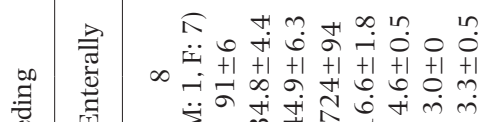

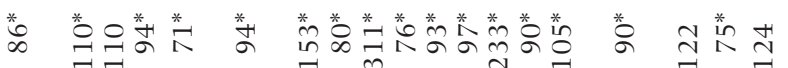

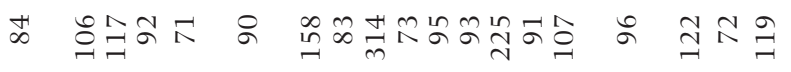

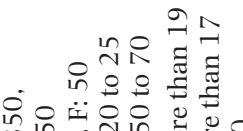

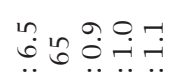

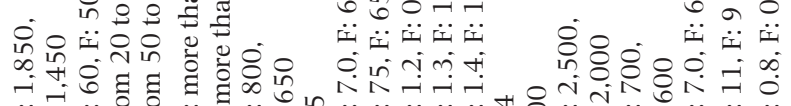

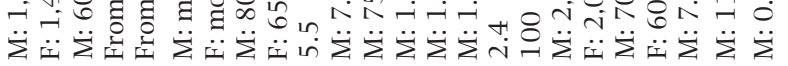
啚 范吕吕

\section{全}

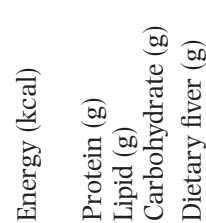

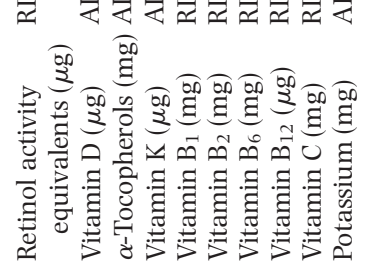

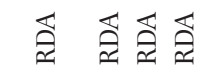

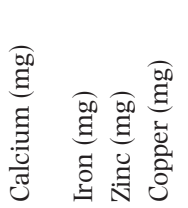


in this study other than nutrient intake levels were indicated as the mean \pm standard deviation. Statistical processing of nutrient intake levels and blood test results was carried out using the Mann-Whitney test based on a level of significance of less than 5\%. In addition, statistical processing of subject attributes, as well as zinc, WBC, RBC, Hb, Ht, TP, Alb, A/G ratio, iron, and copper values was carried out using a single correlation coefficient and multiple regression analysis based on a level of significance of less than 5\%. The PC software SPSS12.0 J for Windows (SPSS Japan Inc.) was used for statistical processing of the results obtained in this study.

\section{RESULTS}

\section{Attributes}

Comparisons of the subjects' attributes were indicated according to type of feeding (oral feeding group and enteral feeding group), type of diet (regular diet group and rice gruel diet group), BMI (18.5 or higher group and under 18.5 group), level of care (light level of care (level 2 to 3 ) and heavy level of care (level 4 to 5), grade of bedriddenness (rank A and B group and rank C group), and grade of cognitive function (rank I and II group and rank III and IV group) as shown in Table 2. Furthermore, the grade of bedriddenness was scored by assigning a score of 1 for rank A, a score of 2 for rank $\mathrm{B}$, and a score of 3 for rank $\mathrm{C}$. In addition, the grade of cognitive function was scored by assigning a score of 1 for rank I, a score of 2 for rank II, a score of 3 for rank III, and a score of 4 for rank IV.

Those attribute parameters for which significant differences were observed were as follows.

With respect to the attribute of type of feeding, the parameters for which the oral feeding group was significantly higher in comparison with those of the enteral feeding group consisted of basal metabolic rate and BMI $(p<0.05)$. Those parameters for which the enteral feeding group was significantly higher in comparison with those of the oral feeding group consisted of level of care, grade of bedriddenness, and grade of cognitive function $(p<0.01)$.

There were no parameters for the attribute of type of diet for which significant differences were observed between the regular diet group and rice gruel diet group.

With respect to the attribute of BMI, those parameters for which the BMI 18.5 or higher group were significantly higher in comparison with the BMI under 18.5 group consisted of body weight and basal metabolic rate $(p<0.01)$. Conversely, grade of bedriddenness was significantly higher in the BMI under 18.5 group $(p<0.05)$.

With respect to the attribute of level of care, those parameters for which the light level of care group was higher in comparison with the heavy level of care group consisted of body weight, basal metabolic rate, and BMI $(p<0.01)$. Conversely, those parameters for which the heavy level of care was higher consisted of the grade of bedriddenness and grade of cognitive function $(p<0.01)$.

With respect to the attribute of the grade of bedriddenness, those parameters for which the rank A and B group was significantly higher than the rank $\mathrm{C}$ group consisted of body weight, basal metabolic rate, and BMI $(p<0.01)$. Conversely, those parameters for which the rank $C$ group was significantly higher consisted of the level of care, and grade of cognitive function $(p<0.01)$.

With respect to the attribute of the grade of cognitive function, those parameters for which the rank I and II group was significantly higher than the rank III and IV group consisted of body weight $(p<0.05)$, basal metabolic rate $(p<0.01)$, and BMI $(p<0.01)$. Conversely, those parameters for which the rank III and IV group was significantly higher consisted of the level of care and grade of bedriddenness $(p<0.01)$.

Nutrient intake levels

The percentages of nutrient intake level of the Dietary Reference Intakes (16) were indicated according to type of feeding, type of diet, BMI, level of care, grade of bedriddenness, and grade of cognitive function, as shown in Table 2.

Those nutrient intake rates for which significant differences were observed in nutrient intake levels were as follows.

With respect to nutrient intake rates according to type of feeding, there were no nutrients for which significant differences were observed between the oral feeding group and enteral feeding group. Furthermore, although the energy intake levels in both groups were below the estimated energy requirement (16), nutrient intake levels satisfied the basal metabolic rates of individual subjects. In addition, the zinc intake levels in both groups were far below the recommended dietary allowance level (16), being $72 \%$ to $78 \%$ of the recommended dietary allowance level (16).

Next, with respect to nutrient intake rates according to type of diet, those nutrients for which the regular diet group was significantly higher in comparison with the rice gruel diet group consisted of energy, protein, dietary fiber, retinol equivalents, vitamin $(\mathrm{V}) \mathrm{D}, \mathrm{VK}, \mathrm{VB}_{12}$, potassium, and calcium $(p<0.01)$. Conversely, those nutrients for which the rice gruel diet group was significantly higher consisted of zinc, carbohydrates, $\alpha$-tocopherol, $\mathrm{VB}_{1}, \mathrm{VB}_{2}, \mathrm{VB}_{6}$ and $\mathrm{VC}(p<0.01)$.

With respect to the nutrient intake rates according to BMI, there were no nutrients for which significant differences were observed between the BMI 18.5 or higher group and the BMI under 18.5 group. Zinc intake levels in the BMI 18.5 or higher group were considerably less than the recommended dietary allowance level (16), being $78 \%$ of the recommended dietary allowance level (16).

With respect to nutrient intake rates according to the level of care, those nutrients for which the light level of care group was significantly higher in comparison with the heavy level of care group consisted of energy $(p<0.01)$, protein $(p<0.05)$, retinol equivalents $(p<0.05)$ and VD $(p<0.05)$. Conversely, those nutrients for which the heavy level of care group was higher consisted of zinc $(p<0.01), \alpha$-tocopherol $(p<0.05), \mathrm{VB}_{1}$ $(p<0.01), \mathrm{VB}_{2}(p<0.01)$ and $\mathrm{VB}_{6}(p<0.01)$.

With respect to the nutrient intake rates according 


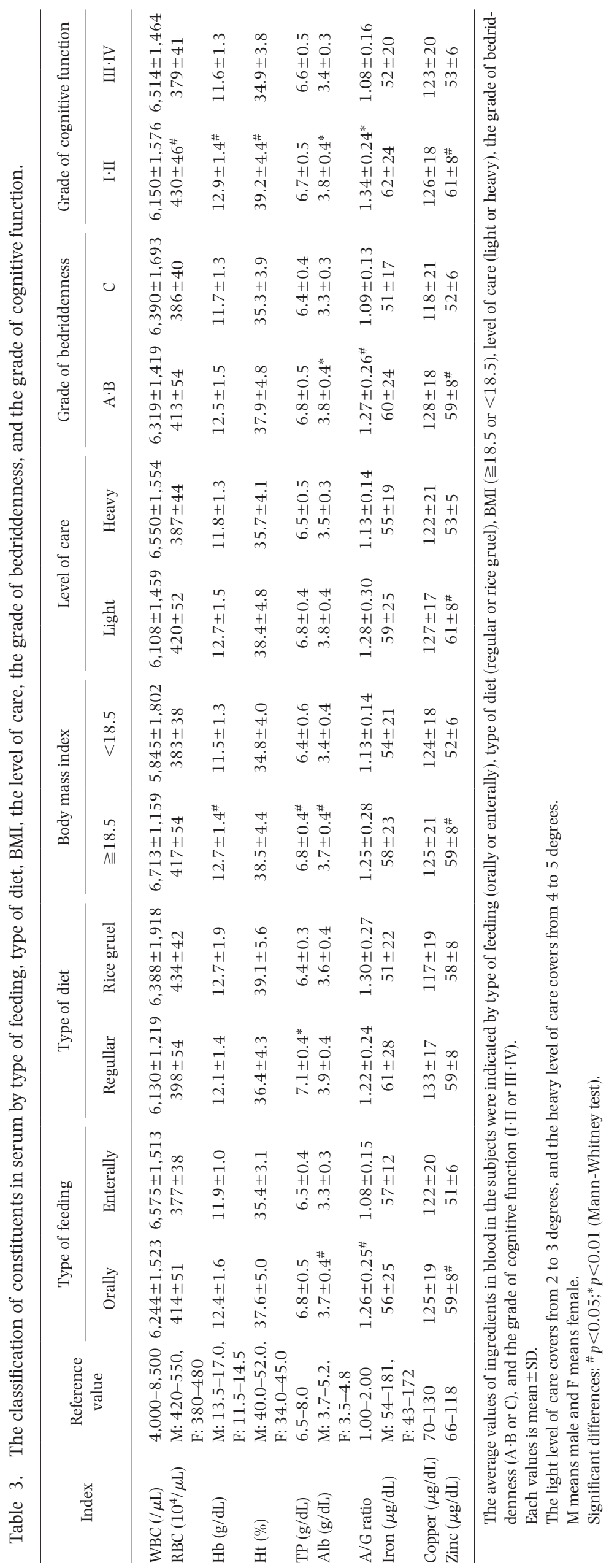


to grade of bedriddenness, those nutrients for which the rank A and B group was significantly higher in comparison with the rank $\mathrm{C}$ group consisted of energy, protein, dietary fiber, VD, VK, $\mathrm{VB}_{12}$, potassium, and calcium (all $p<0.01$ ). Conversely, those nutrients for which the rank $\mathrm{C}$ group was significantly higher consisted of zinc $(p<0.01)$, carbohydrates $(p<0.01), \alpha$-tocopherol $(p<0.01), \mathrm{VB}_{1}(p<0.01), \mathrm{VB}_{2}(p<0.05), \mathrm{VB}_{6}(p<0.05)$, and $\mathrm{VC}(p<0.01)$.

With respect to nutrient intake rates according to grade of cognitive function, those nutrients for which the rank I and II group was significantly higher in comparison with the rank III and IV group consisted of energy $(p<0.01)$, protein $(p<0.01)$, dietary fiber $(p<0.01)$, VD $(p<0.01)$, VK $(p<0.01), \mathrm{VB}_{12}(p<0.01)$, potassium $(p<0.01)$, and calcium $(p<0.05)$. Conversely, those nutrients for which the rank III and IV group was significantly higher consisted of zinc $(p<0.05), \mathrm{VB}_{1}$ $(p<0.05)$, and VC $(p<0.01)$.

Based on the above results, it was indicated that the zinc intake levels of the subjects were organized according to type of feeding, level of care, grade of bedriddenness, and grade of cognitive function, zinc intake rates were 1) higher in the rice gruel diet group than in the regular diet group, 2) higher in the heavy level of care group than in the light level of care group, 3) higher in the bedridden rank $C$ group than in the rank $A$ and B group, and 4) higher in the cognitive rank III and IV group than in the rank I and II group. In addition, although zinc intake levels in the rice gruel diet group satisfied the recommended dietary allowance level of the Dietary Reference Intakes (16), zinc intake rates in the regular diet group as well as both groups for type of feeding, BMI, the level of care, the grade of bedriddenness, and the grade of cognitive function ranged from $72 \%$ to $97 \%$ of the recommended dietary allowance level (16).

Subject blood component levels according to type of feeding, type of diet, BMI, level of care, grade of bedriddenness and grade of cognitive function

Subject blood component levels were indicated according to type of feeding, type of diet, BMI, level of care, grade of bedriddenness, and grade of cognitive function in the same manner as for nutrient intake levels, and are shown in Table 3.

Those components for which significant differences were observed in blood component levels were as follows.

With respect to blood component levels according to type of feeding, those blood components for which the oral feeding group was significantly higher in comparison with the enteral feeding group consisted of zinc, Alb and $\mathrm{A} / \mathrm{G}$ ratio $(p<0.05)$.

With respect to blood component levels according to type of diet, TP was the only blood component for which the regular diet group was significantly higher in comparison with the rice gruel diet group $(p<0.01)$. Furthermore, there were no significant differences observed between the groups with respect to zinc.

With respect to blood component levels according to BMI, those components for which the BMI 18.5 or
Table 4 Multiple regression analysis (step-down procedure method).

\begin{tabular}{lcc}
\hline \multicolumn{1}{c}{ Independent variable } & $\begin{array}{c}\text { Standard } \\
\text { partial regression } \\
\text { coefficient }\end{array}$ & $\begin{array}{c}\text { Significance } \\
\text { probability }\end{array}$ \\
\hline Age & 0.062 & 0.599 \\
Body weight & -1.048 & 0.700 \\
Height & 1.580 & 0.032 \\
Basal metabolic rate & -1.351 & 0.575 \\
Body mass index & 1.723 & 0.047 \\
Level of care\# & -0.603 & 0.014 \\
Grade of bedriddenness & 0.376 & 0.092 \\
Grade of cognitive function & 0.221 & 0.143 \\
RBC & -0.117 & 0.702 \\
Hb & -0.079 & 0.885 \\
Ht & 0.578 & 0.385 \\
TP & -0.009 & 0.951 \\
Alb* & 1.215 & 0.000 \\
Iron & -0.446 & 0.036 \\
Copper & -0.124 & 0.281 \\
\hline
\end{tabular}

$F=11.474(p<0.01)$.

Dependent variable: serum zinc level.

Significant differences: ${ }^{*} p<0.05$; $^{*} p<0.01$.

higher group was significantly higher in comparison with the BMI under 18.5 group consisted of zinc, $\mathrm{Hb}$, $\mathrm{TP}$ and Alb $(p<0.05)$.

With respect to blood component levels according to the level of care, those components for which the light level of care group was significantly higher in comparison with the heavy level of care group consisted only of zinc $(p<0.05)$.

With respect to blood component levels according to the grade of bedriddenness, those components for which the rank A and B group was significantly higher in comparison with the rank $C$ group consisted of zinc $(p<0.05)$, Alb $(p<0.01)$, and A/G ratio $(p<0.05)$.

With respect to blood component levels according to the grade of cognitive function, those components for which the rank I and II group was significantly higher in comparison with the rank III and IV group consisted of zinc $(p<0.05)$, RBC $(p<0.05)$, Hb $(p<0.05)$, Ht $(p<0.05)$, Alb $(p<0.01)$, and $\mathrm{A} / \mathrm{G}$ ratio $(p<0.01)$.

On the basis of the above results, it was indicated that when results for the serum zinc levels of the subjects were organized according to type of feeding, BMI, the level of care, the grade of bedriddenness, and the grade of cognitive function, serum zinc levels were higher in the oral feeding group than in the enteral feeding group, higher in the BMI 18.5 or higher group than in the BMI under 18.5 group, higher in the light level of care group than in the heavy level of care group, higher in the bedridden rank $\mathrm{A}$ and $\mathrm{B}$ group than in the rank $\mathrm{C}$ group, and higher in the cognitive rank I and II group than in the rank III and IV group.

Multiple regression analysis of serum zinc levels based on a single correlation coefficient

The multiple regression analysis carried out by using serum zinc level for the dependent variable and using 
blood component levels measured for each indicator of the subjects' attributes (age, body weight, height, basal metabolic rate, BMI, level of care, grade of bedriddenness, and grade of cognitive funciton) as independent variables is shown in Table 4 . It has been reported that elderly patients suffered decreased muscle mass because of malnutrition (25). On the basis of this finding, we used not only BMI but also height and body weight as independent variables. As a result, those factors that regulate serum zinc levels consisted of BMI $(p<0.05)$, level of care $(p<0.05)$, height $(p<0.05)$, Alb $(p<0.01)$ and iron $(p<0.05)$.

Regression equations between correlation coefficients and RBC, Hb, Ht, TP and Alb demonstrating a high correlation with serum zinc levels according to BMI, level of care, grade of bedriddenness and grade of cognitive function

Those components for which the correlation coefficient between serum zinc level and measured blood component levels was 0.4 or more are shown in Table 5 . Those blood components consisted of $\mathrm{RBC}(p<0.05)$, $\mathrm{Hb}$, Ht $(p<0.05)$, TP $(p<0.05)$, and Alb $(p<0.01)$. Furthermore, there were no significant differences observed between serum zinc levels and dietary zinc intake levels among the subjects.

In addition, regression equations between correlation coefficients and RBC, Hb, Ht, TP, and Alb demonstrating a high correlation with serum zinc levels according to BMI, level of care, grade of bedriddenness, and grade of cognitive function are shown in Table 5.

With respect to the regression equation with the correlation coefficient according to BMI, the correlation coefficient was higher in the BMI group of 18.5 or higher in comparison with the group of BMI under 18.5, and this regression equation demonstrated a steep slope for $\mathrm{RBC}, \mathrm{Hb}$ and $\mathrm{Ht}$.

With respect to the regression equation with the correlation coefficient according to the level of care, the correlation coefficient was higher in the light level of care group in comparison with the heavy level of care group, and this regression equation demonstrated a steep slope for RBC, Hb, Ht, and Alb.

With respect to the regression equation with the correlation coefficient according to the grade of bedriddenness, the correlation coefficient was higher in the rank $\mathrm{A}$ and $\mathrm{B}$ group in comparison with the rank $\mathrm{C}$ group, and this regression equation demonstrated a steep slope for RBC, Hb, Ht and, Alb.

With respect to the regression equation with the correlation coefficient according to the grade of cognitive function, the correlation coefficient was higher in the rank I and II group in comparison with the rank III and IV group, and this regression equation demonstrated a steep slope for all of RBC, Hb, Ht, TP, and Alb.

\section{DISCUSSION}

This study was conducted for the purpose of investigating the manner in which serum zinc levels change according to BMI, level of care, grade of bedriddenness and grade of cognitive function in order to examine the relationship between zinc nutritional status, level of 
care and physical status.

Zinc intake rates among the subjects based on Dietary Reference Intakes (16) were higher in groups having a low ADL index. However, serum zinc levels tended to be higher in groups having a high ADL index. The average serum zinc level of the subjects demonstrated a value of $56 \mu \mathrm{g} / \mathrm{dL}$, and the proportion of subjects having a low serum zinc level of less than $66 \mu \mathrm{g} / \mathrm{dL}$ (26) accounted for a large proportion of all subjects at $84.6 \%$. In addition, among those subjects having low serum zinc levels, the proportions of subjects having a BMI of less than 18.5, having a heavy level of care and being fed enterally accounted for 50.0\%, 63.6\% and 36.4\%, respectively, of all subjects. Moreover, the proportions of three groups of subjects, a group of heavy level of care, a group of BMI of less than 18.5, and a group fed enterally accounted for 53.8\%, 42.3\% and 30.8\%, respectively, of all subjects. All these three groups demonstrated low serum zinc levels.

Those factors determined by multiple regression analysis to have an effect on serum zinc level consisted of BMI, level of care, height, Alb and iron. Kosaka et al. reported that serum zinc levels fluctuate dependending on physical status such as BMI and level of care (18). In this study, correlations and regression equations of blood component values obtained from correlations with serum zinc levels were examined according to both BMI and level of care, which has an effect on the grade of bedriddenness and grade of cognitive function. As a result, among those blood component levels that demonstrated correlations with the four groups, serum zinc levels in the BMI 18.5 or higher group, light level of care group, bedridden rank $\mathrm{A}$ and $\mathrm{B}$ group, and cognitive rank I and II group, positive correlations were obtained with $\mathrm{RBC}, \mathrm{Hb}$, and $\mathrm{Ht}$, and the slopes of their regression equations were large. However, among serum component levels demonstrating correlations with the four groups of serum zinc levels in the BMI under 18.5 group, heavy level of care group, bedridden rank $C$ group, and cognitive rank III and IV group, negative correlations were obtained with $\mathrm{RBC}, \mathrm{Hb}$, and $\mathrm{Ht}$, and the slopes of their regression equations were small, thereby suggesting decreased zinc turnover and bioavailability. On the basis thereof, there is the possibility that zinc nutritional status may fluctuate dependent on the factors such as the physical status of the disabled elderly patients, and particularly on BMI, level of care and grade of bedriddenness involved in evaluation of the ADL index. Zinc has been reported to play an important role in cognitive function mediated by neurotransmitters (27), and appropriate zinc intake levels have been reported to improve cognitive function (28). In this study as well, a correlation was observed between serum zinc levels and grade of cognitive function. On the other hand, it has been indicated that with respect to zinc absorption and bioavailability in the elderly, zinc turnover changes negatively as a result of bedriddenness (29), and that decreased zinc absorption and loss of the ability to retain nutrients in the body is caused by aging $(30,31)$. On the basis of these findings, it may be presumed that zinc absorption and bioavailability in disabled elderly patients differ according to BMI, level of care, grade of bedriddenness and grade of cognitive function.

As already explained, BMI and level of care are factors having an effect on serum zinc levels. It was also determined that Alb and iron are factors having an effect on serum zinc levels and are blood component parameters that indicate protein nutritional status and iron nutritional status. Protein is an essential constituent for the function of cells and organs (32). A positive correlation between zinc and Alb has been observed in numerous reports $(9,13,33)$. In addition, iron is involved in immunity (34). According to a report describing the administration of zinc-fortified bread to women having zinc deficiencies, zinc remarkably improved iron absorption and enhanced iron nutritional status (35). The present study suggested that serum zinc levels fluctuate according to protein and iron nutritional status. On the other hand, zinc is also known to be involved in protein synthesis $(7,36)$ and immunity $(37)$. Thus, it may be presumed that protein and iron nutritional status can be favorably maintained by raising the serum zinc level, while also leading to improved immunity.

The proportion of subjects fed enterally among the subjects of this survey was $30.8 \%$, and all of these subjects demonstrated low serum zinc levels and a heavy level of care. In addition, the proportion of subjects having a BMI of under 18.5 was $75.0 \%$. Despite enterally fed subjects having higher zinc intake rates based on Dietary Reference Intakes in comparison with the oral feeding group, serum zinc levels tended to be lower. It was reported that 10 to $15 \mathrm{mg} / 1,000 \mathrm{kcal}$ of zinc was required in cases of enteral feeding (38), and this amount was adequately satisfied in the subjects of the present study. In examining the intake rates of nutrients other than zinc, the intake rates of energy and protein were observed to be low. The subjects of the present study are at risk to PEM because they require nursing care. Recognized effects of PEM consist of increased mortality rate (1), decreased ADL index (2), longer hospitalization times (3) and decreased immunity (4). In addition, it was reported that a significant number of disabled elderly patients have been reported to demonstrate negative nitrogen turnover (39). Moreover, it has also been indicated that the estimated average required level of protein should be increased for disabled elderly patients, and decreased protein metabolism from skeletal muscle attributable to decreased physical activity (40) and it was also indicated that low energy intake (41) was a reason for this. Thus, energy and protein intake among disabled elderly patients, and particularly those fed enterally, is important in terms of preventing PEM, and it will be necessary to examine these intake levels in greater detail in the future. On the other hand, the presence of zinc deficiency has been reported in PEM patients (42). It has been observed that decreased mortality rates (13), decreased ADL indices (13), the occurrence of infections in long-term hospitalized patients (11) and decreased immunity (14) were caused by low serum zinc levels. In addition, it has also been reported 
that there was a link between zinc homeostasis and energy metabolism (43). Based on these findings, it may be suggested that it is necessary to enhance not only zinc intake level, but also energy and protein intake levels, in order to increase serum zinc levels in persons undergoing enteral feeding.

\section{CONCLUSION}

The present study made it clear that the zinc nutritional status of disabled elderly patients varied according to four factors: BMI level of care, grade of bedriddenness, and grade of cognitive function.

In the future, it will be necessary to more closely examine the intake levels of zinc, protein, energy in order to restore the low serum zinc levels to reference level, so as to improve and maintain the ADL indices of disabled elderly patients who are at risk for PEM.

\section{Acknowledgments}

We would like to thank for the disabled elderly patients and the staff of the nursing facilities who cooperated in this study.

\section{REFERENCES}

1) Matsuda A. 1998. The study on the nutritional management services for the elderly persons. National Institute of Health Service Management, National Institute of Health and Nutrition (in Japanese).

2) Matsuda A 1996. The study on the nutritional management of patients at home. National Institute of Health Service Management, National Institute of Health and Nutrition (in Japanese).

3) Bernstein LH, Shaw-Stiffel TA, Schorow M, Brouillette R. 1993. Financial implications of malnutrition. Clin Lab Med 13: 491-507.

4) Lesourd BM. 1997. Nutrition and immunity in the elderly: modification of immune responses with nutritional treatments. Am J Clin Nutr 66: 478S-484S.

5) Gomi I, Sugiyama M, Kajii F, Ogoshi H, Ando T, Koyama H. 2005. Protein energy malnutrition of the elderly persons institutionalized in the combined type care facility. JNCM 4: 147-155 (in Japanese).

6) Jose H. 2003. The significance of measuring the albumin level of patients being cared for at home. Monthly Hodanren 643: 61-64 (in Japanese).

7) Shazia Q, Mohammad ZH, Rahman T, Shekhar HU. 2012. Correlation of oxidative stress with serum trace element levels and antioxidant enzyme status in beta thalassemia major patients: A review of the literature. Anemia 201 2: 1-7.

8) Kurasawa R, Kubori S, Kamioka H, Okada S, Matsumura O. 2005 . Zinc deficiency in aged residents and lowered serum-zinc-concentration as population level in the same rural region. Biomed Res Trace Elem 16: 61-65 (in Japanese).

9) Saito N. 2005. The investigation on serum copper(Cu)/ zinc(Zn) ratio in elderly inpatients. Biomed Res Trace Elem 16: 258-260 (in Japanese).

10) Leibovitz A, Lubart E, Wainstein J, Dror Y, Segal R. 2009. Serum trace elements in elderly frail patients with oropharyngeal dysphagia. J Nutr Sci Vitaminol 55: 407-411.

11) Ukita T, Oidov B, Kawada E, Ohyama Y, Morita T, Tamura
J. 2008. Serum zinc deficiency increases susceptibility to infection in older patients who have long-term hospitalizations. Biomed Res Trace Elem 19: 260-264.

12) Oriishi T, Kumashiro R, Itou M, Toyonaga A, Sata M. 2003. Physical changes related to long-term bedridden condition in patients with cerebrovascular disease. Digestion \& Absorption 26: 60-63 (in Japanese).

13) Jose H. 1999. Studies on serum levels of zinc in the elderly being cared for at home. JJPA 14: 21-25 (in Japanese).

14) High KP. 2001. Nutritional strategies to boost immunity and prevent infection in elderly individuals. Clin Infect Diss 33: 1892-1900.

15) Kosaka K, Konishi Y, Yamashita S, Kikunaga S. 2013. A study on the two relationships, between serum zinc concentration and the intake of zinc, and between serum zinc concentration and the hematological consistent associated with serum zinc concentration in the disabled elderly patients in the health facility. J Integr Stud Diet Habits 23: 207-216 (in Japanese).

16) Ministry of Health, Labour and Welfare. 2009. Dietary Reference Intakes for Japanese, 2010, p 43-275. Daiichi Shuppan, Tokyo (in Japanese).

17) Ministry of Health, Labour and Welfare. 2006. The National Health and Nutrition Survey Japan 2004, p 60-63, 106-119, 158-159, 163, Daiichi Shuppan, Tokyo (in Japanese).

18) Kosaka K, Konishi Y, Kikunaga S. 2012. The change of zinc nutritional status according to the value of BMI, and the level of ADL and care in the disabled elderly patients in nursing facility. Biomed Res Trace Elem 23: 208-216 (in Japanese).

19) Kawanishi H. 2003. Seirei Nutritional Care and Management Manual, p 3-14. Ishiyaku Publishers, Tokyo (in Japanese).

20) Ministry of Health, Labour and Welfare. 2009. Certification of Long-term Care Need. [Online]. Available: http://www.mhlw.go.jp/seisakunitsuite/bunya/huku shi_kaigo/kaigo_koureisha/nintei/index.html [accessed April 25, 2013].

21) Ministry of Health, Labour and Welfare. 2006. Care. Elderly Welfare. [Online]. Available: http://www.mhlw. go.jp/topics/kaigo/kentou/15kourei/sankou $4 . \mathrm{html}$ [accessed April 25, 2013].

22) Japan Dietetic Association. 2011. Handbook of the Diet for Enteral Nutrition, p 154, 164. Bunkodo, Tokyo (in Japanese).

23) Tamagawa K, Kuchiba N, Kido S. 2008. A Manual for Exercise in Clinical Nutrition, p 1-20. Ishiyaku Publishers, Tokyo (in Japanese).

24) Takagi Y. 2002. Assessment of nutritional status and abnormality on trace element. Japanese Journal of Nutritional Assessment 19: 9-17 (in Japanese).

25) Amagai T. 2011. MNA Guide Book Nutrition Screening Tool for the Elderly, p 13. Ishiyaku Publishers, Tokyo (in Japanese).

26) Kanai I. 1998. Kanai's Manual of Clinical Laboratory Medicine, p 4-9. Kanehara-Shuppan, Tokyo (in Japanese).

27) Nakashima AS, Dyck RH. 2009. Zinc and cortical plasticity. Brain Res Rev 59: 347-373.

28) Ortega RM, Requejo AM, Andrés P, López-Sobaler AM, Quintas ME, Redondo MR, Navia B, Rivas T. 1997. Dietary intake and cognitive function in a group of elderly people. Am J Clin Nutr 66: 803-809. 
29) Krebs JM, Schneider VS, Leblanc AD, Kuo MC, Spector E, Lane HW. 1993. Zinc and copper balances in healthy adult males during and after $17 \mathrm{wk}$ of bed rest. Am J Clin Nutr 58: 897-901.

30) Miyata S. 2007. Zinc deficiency in the elderly. Japanese Journal of Geriatrics 44: 677-689 (in Japanese).

31) Itokawa Y. 2003. The clinical study on the trace element deficiency of the elderly persons. Journal of the Japan Medical Association 5: 635-638 (in Japanese).

32) Food and Nutrition Board, Institute of Medicine. 2002. Dietary Reference Intakes for Energy, Carbohydrate, Fiber, Fat, Fatty Acids, Cholesterol, Protein, and Amino Acids (Macronutrients). National Academies Press, Washington, DC.

33) Goda F, Inukai M, Okuyama H, Himoto T, Masugata $H$, Senda S. 2010. The feasibility study of the necessity of supplementations of trace elements in healthy elderly subjects. J.JSPEN 25: 823-829 (in Japanese).

34) Brunton JA, Ball RO, Pencharz PB. 2000. Current total parenteral nutrition solutions for the neonate are inadequate. Curr Opin Clin Nutr Metabo Care 3: 299-304.

35) Badii A, Nekouei N, Fazilati M, Shahedi M, Badiei S. 2012. Effect of consuming zinc-fortified bread on serum zinc and iron status of zinc-deficient women: a double blind, randomized clinical trial. Int J Prev Med 3: S124-S130.

36) Prasad AS. 1995. Zinc: an overview. Nutrition 11: 93-99.
37) Kimura S, Kobayashi S. 2002. Present Knowledge in Nutrition, 8th ed. p 342-355. Kenpakusha, Tokyo (in Japanese).

38) Wakugami K. 2008. Difference between appropriate amount of trace element for long term enteral nutrition and dietry reference intakes 2005. Biomed Res Trace Elem 19: 13-21 (in Japanese).

39) Ebisawa H, Ozeki T, Ichikawa M, Fujita Y. 1992. Protein intake for maintenance of nitrogen balances in the elderly. Reports of the Research Committee of Essential Amino Acids 136: 9-12 (in Japanese).

40) Millward DJ, Bowtell JL, Pacy P, Rennie MJ. 1994. Physical activity, protein metabolism and protein requirements. Pros Nutr Soc 53: 223-240.

41) Pellett PL, Young VR. 1992. The effect of different levels of energy intake on protein metabolism and of different levels of protein intake on energy metabolism: A statistical evaluation from the published literature. [Online]. Available: http://archive.unu.edu/unupress/food2/UID07E/ UID07E0B.HTM [accessed April 25, 2013].

42) Lesourd BM. 1997. Nutrition and immunity in the elderly: modification of immune responses with nutritional treatments. Am J Cin Nutr 66: 478S-484S.

43) Cunnane SC. 1982. Differential regulation of essential fatty acid metabolism to the prostaglandins: possible basis for the interaction of zinc and copper in biological systems. Prog Lipid Res 21: 73-90. 